\title{
Cisplatin liposome and 6-amino nicotinamide combination to overcome drug resistance in ovarian cancer cells
}

\author{
Daniela Catanzaro ${ }^{1, *}$, Silvia Nicolosi ${ }^{1, *}{ }^{*}$, Veronica Cocetta $^{1}$, Marika Salvalaio ${ }^{1}$, \\ Andrea Pagetta ${ }^{1}$, Eugenio Ragazzi ${ }^{1}$, Monica Montopoli ${ }^{1,2}$ and Gianfranco Pasut ${ }^{1,3}$ \\ ${ }^{1}$ Department of Pharmaceutical and Pharmacological Sciences, University of Padua, Padua, Italy \\ ${ }^{2}$ Venetian Institute of Molecular Medicine, Padova, Italy \\ ${ }^{3}$ Veneto Institute of Oncology IOV, IRCCS, Padua, Italy \\ ${ }^{*}$ These authors have contributed equally to the work \\ Correspondence to: Monica Montopoli, email: monica.montopoli@unipd.it \\ Gianfranco Pasut, email: gianfranco.pasut@unipd.it \\ Keywords: Cisplatin; drug resistance; drug delivery; liposomes; combination therapy \\ Received: September 01, $2017 \quad$ Accepted: February 27, $2018 \quad$ Published: March 30, 2018 \\ Copyright: Catanzaro et al. This is an open-access article distributed under the terms of the Creative Commons Attribution License \\ 3.0 (CC BY 3.0), which permits unrestricted use, distribution, and reproduction in any medium, provided the original author and \\ source are credited.
}

\section{ABSTRACT}

Ovarian cancer is an aggressive and lethal cancer usually treated by cytoreductive surgery followed by chemotherapy. Unfortunately, after an initial response, many patients relapse owing mainly to the development of resistance against the standard chemotherapy regime, carboplatin/paclitaxel, which is also affected by heavy side effects. In view to addressing such issues here, an association of liposomal cisplatin with 6-amino nicotinamide is investigated. It is known that resistant cells increase their demand for glucose, which is partially redirected toward the pentose phosphate pathway (PPP). Interestingly, we have found that also a cisplatin-resistant subclone of the ovarian cancer cells IGROV1 switch their metabolism toward the glycolytic pathway and rely on PPP to elude cisplatin cytotoxicity. The drug 6 -amino nicotinamide, an inhibitor of the enzyme glucose-6-phosphate dehydrogenase (the rate-limiting step of the PPP) can restore the sensitivity of resistant cells to cisplatin. Then, to reduce the toxicity of cisplatin and prolong its action, a lyophilized stealth liposomal formulation of cisplatin was developed. The combination treatment of liposomal cisplatin and 6-amino nicotinamide showed promising cytotoxic activities in drug-resistant cells and a prolonged pharmacokinetics in rats, thus opening the way for a new therapeutic option against ovarian cancer.

\section{INTRODUCTION}

Ovarian cancer (OC) is one of the most aggressive and lethal gynecological cancers with an incidence in 2012 of about 240,000 women/y and a mortality of about 150,000 women/y [1]. Nevertheless, the incidence and mortality forecasts of this tumor are expected to increase in the next years [1], and the 5-year survival rate is approximately $45 \%$. One of the main issues of OC is that about $70 \%$ of patients are diagnosed with advanced disease (FIGO III/IV tumor stages), with several tumor nodes present and disseminated in the peritoneal cavity, thus impacting the success of treatment [2]. Furthermore, ascites can be a reservoir of aggressive cancer cells that facilitate the peritoneal dissemination. Consequently, any new approach of OC therapy should target various kinds of tumoral cells and/or tissues. Currently, standard initial management of advanced stages of OC is cytoreductive surgery [3], followed by a chemotherapy based on an association of carboplatin-paclitaxel [4-6]. Unfortunately, although an initial $70-80 \%$ response rate, most patients relapse due to development of diseases resistant to chemotherapy [7]. Carboplatin/paclitaxel therapy is limited by the risk of cumulative peripheral neuropathy 
[8]. Better results have been achieved in clinical trials with cisplatin when the doses used are doubled, but this approach is impractical due to the associated toxicity with a high-dose chemotherapy. In fact, anticancer drugs are usually low molecular weight molecules presenting poor bioavailability, low water solubility, non-specific body distribution and very modest cancer cell selectivity; thus they have several systemic toxicities with a consequent low patient compliance. It is therefore evident that unravelling the mechanisms causing chemoresistance is crucial for personalized therapy and the improvement of patients' long-term survival.

In order to develop innovative strategies enabling to limit not only the onset of cisplatin-resistance mechanisms but also to reduce its dosage in chemotherapy, we explored which pathways are exploited by human ovarian cancer cells resistant to cisplatin (IGROV1 Pt) to escape drug cytotoxicity. Cisplatin resistance is a multifactorial phenomenon, whose molecular mechanisms are still not completely understood. In our previous studies, we demonstrated that, among others, also deregulated metabolism might be involved in the onset of drug resistance revealing that cisplatin-resistant ovarian cancer cells (C13) underpin profound metabolic changes as compared with their sensitive counterpart $(2008)[9,10]$. In particular, we observed that resistant cells increase their demand for glucose that is partially redirected toward the pentose phosphate pathway (PPP). Here we investigated the hypothesis that IGROV1 cisplatin-resistant cells might present a similarly altered phenotype that could be effectively targeted to restore drug sensitivity. Interestingly, we have found that IGROV1 Pt cells switch their metabolism toward the glycolytic pathway and rely on PPP to elude cisplatin cytotoxicity. Moreover, It has been demonstrated that the drug sensitivity could be restored by inhibiting the enzyme glucose-6-phosphate dehydrogenase (G6PDH), the rate-limiting step of the PPP, with 6-amino nicotinamide (6-AN) [10].

Given these promising data about the metabolic phenotype of IGROV1 PT cells, this work aimed to develop a strategy able to target PPP and, at the same time, to reduce cisplatin toxicity by proposing a new combination approach of 6-AN and liposomes loaded with cisplatin.

Cisplatin-loaded liposomes are a good strategy to reduce side effects and improve the antitumor efficacy of the drug $[11,12]$. Currently, there are different platin-based formulations in clinical trials such as Lipoplatin, loaded with cisplatin [13], and Lipoxal, loaded with oxaliplatin $[14,15]$. Most of these platin-loaded liposomes are based on saturated phospholipids, which yield slow rate of drug release with a consequent low antitumor efficacy in vitro but better liposome stability in vivo [16]. In fact, the lipid composition, and therefore the transition temperature of phospholipids, is a very important criterion for the development of a successful liposomal drug delivery system of anticancer drugs. The rate of cisplatin release can be increased by using unsaturated phospholipids and a reduced amount of cholesterol, thus increasing the fluidity and permeability of phospholipid bilayer [17]. In fact, in the case of $\mathrm{OC}$, the liposomal formulation will be injected intraperitoneally and, therefore, it is relevant that the loaded drug is released with a favorable kinetic allowing the desired cytotoxic effect. On the other hand, such formulation might be less stable in vivo, but this issue can be circumvented through a polyethylene glycol (PEG) coating of the vesicles' surface, an approach known as PEGylation and that prolongs the pharmacokinetic profile of liposomes [18]. Usually, the polymer is anchored to the phospholipid bilayers by a distearoyl phosphoethanolamine (DSPE) covalently coupled to PEG, PEG-DSPE. The so-called stealth liposomes (SLs) outperformed the classic naked liposomes (CL) in terms of circulation half-life in vivo and this technology has been used in clinical practice for more than 20 years [19]. It has been demonstrated that the hydrophobic anchor, interacting with the phospholipid bilayer, is extremely relevant to maintain the PEG chain attached to the surface of liposomes [20], thus avoiding interaction with blood proteins that promote liposome clearance [21]. To strengthen such interaction and consequently gain a further stabilization of the PEG coating we recently proposed a specific PEG-dendron able to carry up to four DSPE molecules. Such PEG-dendron-(DSPE) derivative yielded liposomes with a prolonged pharmacokinetic in vivo, gaining a further extension of the circulation half-life of these coated liposomes with respect to SLs; they were called super-stealth liposomes (SSLs) [22].

Owing to the interesting features of SSLs, we here investigated the potential of such delivery system, prepared with unsaturated phospholipids as the main constituent, in overcoming OC resistance to cisplatin by testing in vitro a combination of liposomal cisplatin and 6-AN.

\section{RESULTS}

\section{Preparation and characterization of cisplatin- loaded liposomes}

Initially, the CL liposomes were prepared by using only S75 and cholesterol (8:2 molar ratio). The hydrodynamic diameters of liposomes were approximately between $110-140 \mathrm{~nm}$ with a polydispersity index (PDI) of 0.1 . This formulation showed a good encapsulation with an encapsulation efficiency of $18.5 \% \pm 2.47(0.85 \%$ cisplatin/ lipid w/w). Cisplatin release studies of such formulation showed a very fast release of the encapsulated drug with almost $50 \%$ and $80 \%$ of cisplatin released in only $5 \mathrm{~h}$ and $24 \mathrm{~h}$, respectively, (Figure 1A). To circumvent this issue about one-third of the phospholipids in the formulations was substituted with HSPC. These formulations presented 
a higher cisplatin encapsulation, as shown in Table 1, and a mean particle size comparable to previous formulations while, as desired, the cisplatin release was slower with $40-50 \%$ of the drug still entrapped in the liposomes at 24 $\mathrm{h}$ (Figure 1B). Although the drug release was optimized, the cisplatin release itself hampered the storage of the liposomes in the solution owing the accumulation of free cisplatin that would affect, the next in vitro/in vivo studies. Consequently, a lyophilized liposomal formulation was developed and the lyophilization process was optimized for such liposomes, thus allowing long-term storage without cisplatin release.

The liposomes were lyophilized and the effect of two disaccharides (trehalose and sucrose) as cryoprotectant was evaluated. Lyophilization can alter the organization of liposome bilayer causing vesicle disruption, with changes in vesicles size and PDI, and drug release. In this study, the changes of vesicles size and the PDI were measured before and after lyophilization by DLS. Different molar ratios of cryoprotectant with respect to phospholipids were tested by adding the disaccharide in the solution used for the hydration of the thin lipid film and in the purified liposome solution after the elimination of free cisplatin. The values of vesicles size and PDI of CL before and after lyophilization, are shown in Table 2. Lyophilization induced a dramatic increase on size and PDI values of liposomes when low amounts of cryoprotectant were used while a good protection was achieved for both cryoprotectants at the ratio 1:6 phospholipid/cryoprotectant (w/w). The lyophilization process did not affect the percentage of drug encapsulation into liposomes formulation. Similar results were obtained for $\mathrm{SSL}_{2}$ and $\mathrm{SSL}_{4}$.

Sucrose was more effective in preserving the liposomes stability also at lower amounts with respect to trehalose. Although the interesting cryoprotective effect of sucrose, this disaccharide was affecting the in vitro

A

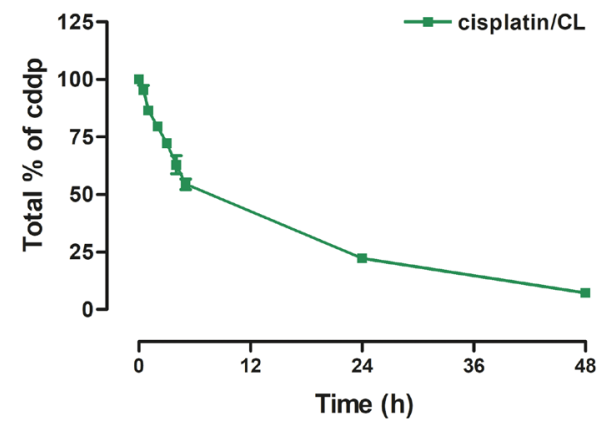

cytotoxicity investigation because it induced cells growth and protected cisplatin-resistant cells against the activity of the drug (Supplementary Figure 1). Consequently, all the following studies have been performed with lyophilized liposomes containing trehalose as cryoprotectant at the molar ratio of 1:6 phospholipid/cryoprotectant (w/w).

Serum stability of CL, $\mathrm{SSL}_{2} \mathrm{~s}$, and $\mathrm{SSL}_{4} \mathrm{~S}$ incubated up to $24 \mathrm{~h}$ in FBS/PBS (50/50) mixture, was evaluated by monitoring the size of vesicles and showed no significant changes of size and PDI during the time for all formulations.

\section{Glucose metabolism in cisplatin-resistant cells}

In line with our previous data, the cisplatin resistant cells exhibited a glucose-dependent phenotype [10]. In fact, the treatment with the glycolysis inhibitor 2-deoxyglucose (2DG) reduced cell viability of both cell lines and in particular that of resistant cells $(-60 \%)$ (Figure 2A). mRNA expression of glycolysis enzymes was analyzed and as shown in Figure 2B, resistant cells presented higher mRNA levels of glycolytic enzymes compared to the wild type. In particular GLUT-1 mRNA resulted in 2.2 fold increase. The glucose transporter GLUT1 expression resulted up-regulated (1.33 fold) in resistant cells (Figure 2C). In line with these data, IGROV1 PT cells presented increased glucose uptake (Figure 2D). Together, these data showed that cisplatinresistant cells are more dependent on glucose when compared to the cisplatin-sensitive counterpart.

\section{Glucose-6-Phosphate Dehydrogenase (G6PDH): Target for cisplatin-resistant cells}

G6PDH is a key enzyme of the PPP activity. G6PDH mRNA (Figure 3A) and protein (Figure 3B) expressions were increased in IGROV1 PT cells when compared to
B

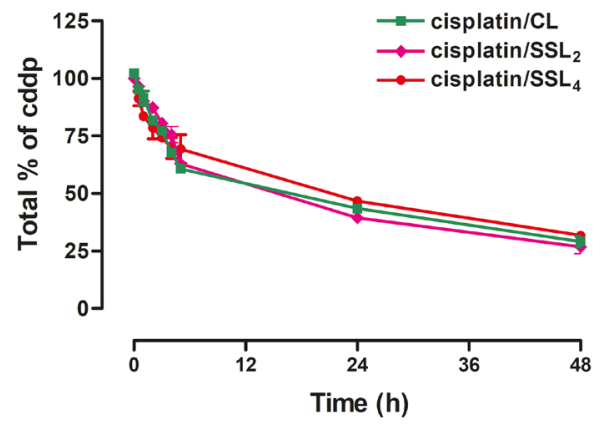

Figure 1: Cisplatin release from different liposomal formulations. (A) Cisplatin release from CL liposomes prepared with only S75 and cholesterol (8:2 molar ratio). (B) Cisplatin release from CL, SSL 2 , and SSL liposomes prepared with S75:HSPC:Chol (63:25:12) for CL and of S75:HSPC:Chol:PEG-DSPE or PEG-DSPE $_{4}(60: 24: 12: 4)$ for $\mathrm{SSL}_{2}$ and $\mathrm{SSL}_{4}$, respectively. Data are the mean $\pm \mathrm{SEM}$ of 3 independent experiments. 
Table 1: Encapsulation efficiency and cisplatin loading of liposomal formulations $(\mathbf{n}=\mathbf{3})$

\begin{tabular}{lcc}
\hline Formulation & cisplatin encapsulation efficiency (\%) & cisplatin/lipid (\% w/w) \\
\hline cisplatin/CL & $25.1 \pm 0.71$ & $1.14 \pm 0.03$ \\
cisplatin/SSL & $25.7 \pm 0.94$ & $1.19 \pm 0.04$ \\
cisplatin/SSL & $25.9 \pm 0.86$ & $1.21 \pm 0.04$ \\
\hline
\end{tabular}

Table 2: Investigation of different amounts of cryoprotectant for liposome stabilization during lyophilization $(\mathrm{n}=\mathbf{3})$

\begin{tabular}{|c|c|c|c|c|}
\hline \multirow{2}{*}{$\begin{array}{l}\text { Molar ratio } \\
\text { Phospholipids / } \\
\text { Cryoprotectant }\end{array}$} & $\begin{array}{c}\text { Mean Particle Size } \\
(\mathbf{n m} \pm \mathrm{SD})\end{array}$ & $\mathrm{PDI} \pm \mathrm{SD}$ & $\begin{array}{c}\text { Mean Particle Size } \\
(\mathrm{nm} \pm \mathrm{DS})\end{array}$ & $\mathrm{PDI} \pm \mathrm{SD}$ \\
\hline & \multicolumn{2}{|c|}{ Before lyophilisation } & \multicolumn{2}{|c|}{ After lyophilisation } \\
\hline \multicolumn{5}{|c|}{ Sucrose } \\
\hline CL 1:2 & $136 \pm 0.9$ & $0.080 \pm 0.009$ & $557 \pm 1.12$ & $0.451 \pm 0.052$ \\
\hline CL 1:5 & $139 \pm 0.8$ & $0.098 \pm 0.007$ & $145 \pm 1.2$ & $0.141 \pm 0.006$ \\
\hline \multicolumn{5}{|c|}{ Trehalose } \\
\hline CL $1: 2$ & $140.9 \pm 1.6$ & $0.098 \pm 0.006$ & $657 \pm 1.52$ & $0.651 \pm 0.05$ \\
\hline CL 1:5 & $120.4 \pm 1.2$ & $0.082 \pm 0.022$ & $235 \pm 1.1$ & $0.21 \pm 0.06$ \\
\hline CL 1:6 & $132.2 \pm 1.1$ & $0.062 \pm 0.011$ & $128 \pm 1.15$ & $0.082 \pm 0.022$ \\
\hline
\end{tabular}

the sensitive counterpart (3.5 fold). Also, we evaluated the G6PDH activity, which was increased in IGROV1 PT cells in comparison to IGROV1 WT (Figure 3C). In order to confirm the specific phenotype, cells were incubated with a competitive G6PDH inhibitor: 6-AN [10]. As shown in Figure 3D, the cell viability was analyzed after $24 \mathrm{~h}$ treatment with 6 -AN $(0.5-500 \mu \mathrm{M})$. The IGROV1 PT resistant cells, as compared to cisplatin-sensitive cells, were significantly more sensitive to 6-AN at the highest drug concentration. In order to verify the effects of the association of 6-AN with cisplatin at concentrations lower than its $\mathrm{IC}_{50}$ (Supplementary Table 3), isobolographic analysis (Figure 3E-3F) and correlated combination index (Supplementary Table 2) were calculated based on the data reported in Supplementary Table 1. In IGROV1 WT cells, the approximate linearity of the iso-effective concentrations (producing $25 \%$ of cytotoxic effect) suggests no interaction between the two drugs (Figure 3E). In the IGROV1 PT, a synergism was found (Figure 3F), but at higher concentrations of 6-AN. These results confirmed that cisplatin-resistant cells present a phenotype that has an increased dependence on glucose, is more sensitive to glycolysis inhibition and overexpressed PPP when compared to the cisplatin-sensitive counterpart.

\section{Cytotoxicity of liposomal cisplatin formulations}

Cell viability assays of different cisplatin liposomal formulations $\left(\mathrm{CL}, \mathrm{SSL}_{2}\right.$, and $\mathrm{SSL}_{4}$ ) were carried out on sensitive and resistant cells. Empty liposomes did not show any cytotoxic effect in both cell lines at the concentrations used with the cisplatin loaded liposomes (supplementary material Supplementary Figure 2).

The effect on cell viability of cisplatin-loaded CLs, $\mathrm{SSL}_{2} \mathrm{~s}$, and $\mathrm{SSL}_{4} \mathrm{~s}$ (0.1-5 $\mu \mathrm{M}$ cisplatin equiv.) after $24 \mathrm{~h}$ treatment is shown in Figure 4. All liposomes presented similar concentration-dependent cytotoxic activity in both cell lines. These activities were also comparable to that of free cisplatin.

\section{Pharmacokinetics of cisplatin-loaded liposomes}

The pharmacokinetic profiles of free cisplatin and cisplatin-loaded CLs, $\mathrm{SSL}_{2} \mathrm{~s}$, and $\mathrm{SSL}_{4} \mathrm{~s}$ were investigated in female Lewis rats after a single bolus injection at $3 \mathrm{mg} /$ $\mathrm{kg}$ cisplatin equiv. (Figure 5). The blood concentration of free cisplatin decreased rapidly after injection and the drug was not detectable after $48 \mathrm{~h}$. As expected all liposomal formulations of cisplatin showed a prolongation in the pharmacokinetic profile with respect to the free drug. Both SSLs outperformed the CLs, in particular, $\mathrm{SSL}_{4} \mathrm{~s}$ showed values of elimination half-life and area under the curve 2-fold and 3-fold higher than CLs (Table 3).

\section{Confocal microscope}

Owing to the better pharmacokinetic performance of $\mathrm{SSL}_{4} \mathrm{~S}$, the next characterizations have taken into 
consideration only such formulation. Time-lapse/live confocal laser scanning microscope images (Figure 6) showed cellular internalization of fluorescein-labelled $0.5 \mu \mathrm{M}$ cisplatin/ $\mathrm{SSL}_{4} \mathrm{~s}$, following $6 \mathrm{~h}$ of treatment. The cell membrane of both sensitive and resistant cell lines was labeled with a CellMask ${ }^{\mathrm{TM}}$ Orange Plasma membrane Stains. As shown in Figure 6, cisplatin/ $\mathrm{SSL}_{4}$ interacted with cells and the fluorescence intensity was higher in wild-type with respect to resistant cell line. The fluorescence of fluorescein was co-localized with the membrane suggesting the fusion of the liposomes with the cells and the consequent release of cisplatin in the cytoplasm.

\section{Combination activity of cisplatin/ $\mathrm{SSL}_{4}$ with 6-AN}

To evaluate the effect of G6PDH inhibition by the 6-AN and cytotoxic activity of cisplatin, in free or liposomal form, the two compounds were tested in IGROV1 WT and IGROV1 PT. The concentration of cisplatin equiv. was fixed at $0.5 \mu \mathrm{M}$, lower than cisplatin $\mathrm{IC}_{50}$ (reported in Supplementary Table 3), while increasing doses of 6-AN $(1-10 \mu \mathrm{M})$ were tested (Figure 7). In IGROV1 WT the cell cytotoxicity was caused prevalently by cisplatin (free or $\mathrm{SSL}_{4}$ ). On the contrary, in resistant cells, the effect of the combination of $6-\mathrm{AN} 1 \mu \mathrm{M}$ with $0.5 \mu \mathrm{M}$ cisplatin $/ \mathrm{SSL}_{4}$
A
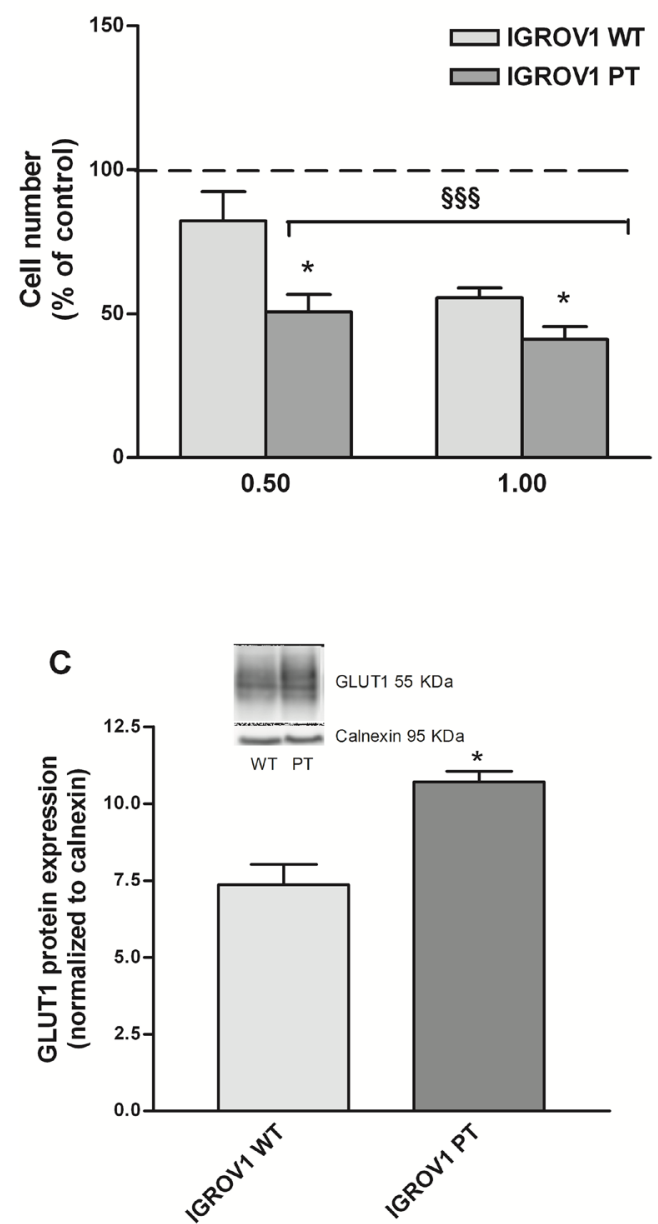

B

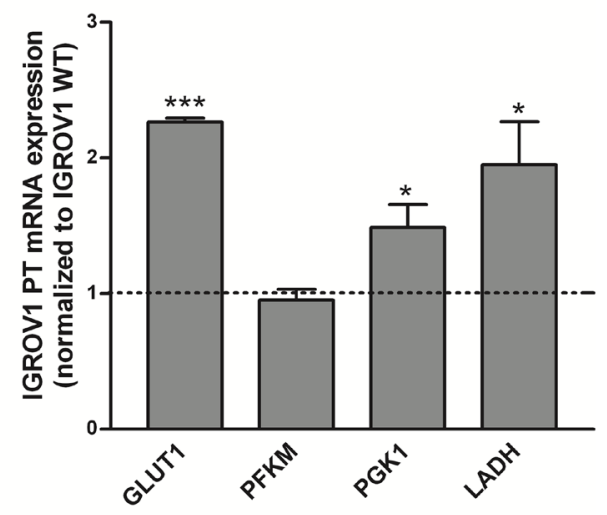

D

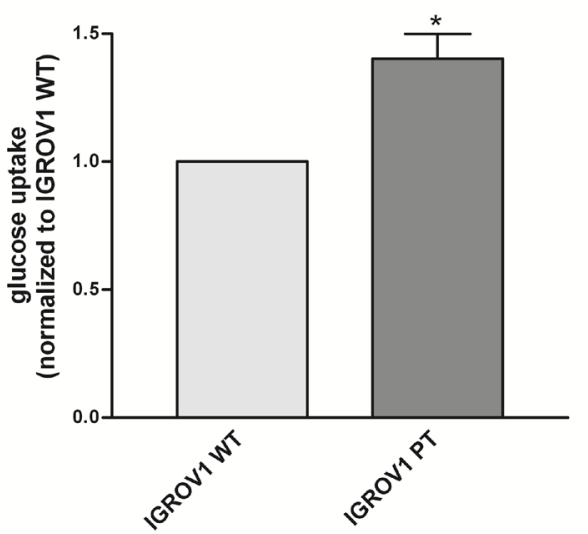

Figure 2: IGROV1 PT cells present an increased dependency on glucose. (A) Cell viability after 24 hours of treatment with a glucose-free medium added with 0.5 and 1mM 2-DG. Data are expressed as the percentage of cell number compared to control. (B) Key genes mRNA levels involved in the glycolytic flux measured by qRT-PCR. All genes were normalized to calnexin as endogenous control and data are expressed as a ratio of IGROV1 PT to IGROV1 WT. (C) GLUT1 protein expression measured by western blotting. GLUT1 was normalized to calnexin. (D) Glucose uptake measured after incubation with the glucose analog 6-NBDG. Data are normalized to cisplatin-sensitive cells. Data are the mean \pm SEM of at least 3-5 independent cultures. ${ }^{* * *} p<0.001,{ }^{*} p<0.05$; IGROV1 PT $v s$ IGROV1 WT. $\S \S \S p<0.001$; treatment $v s$ control. 
A

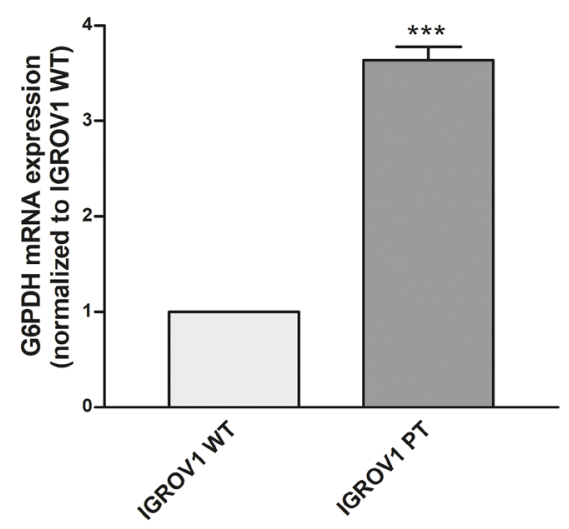

C

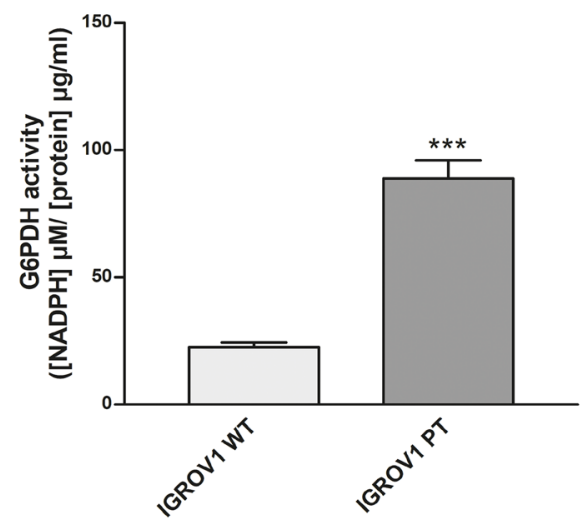

E

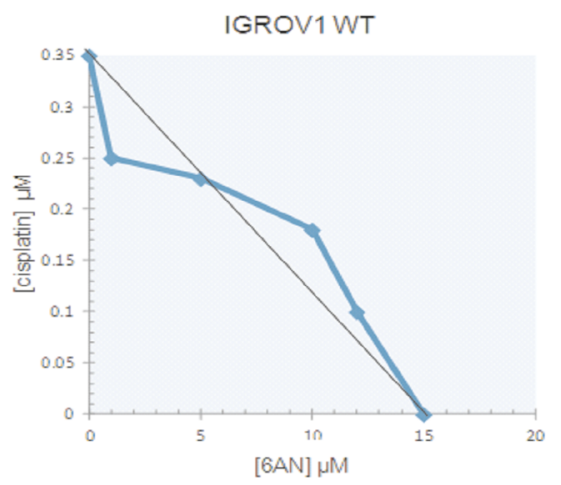

B

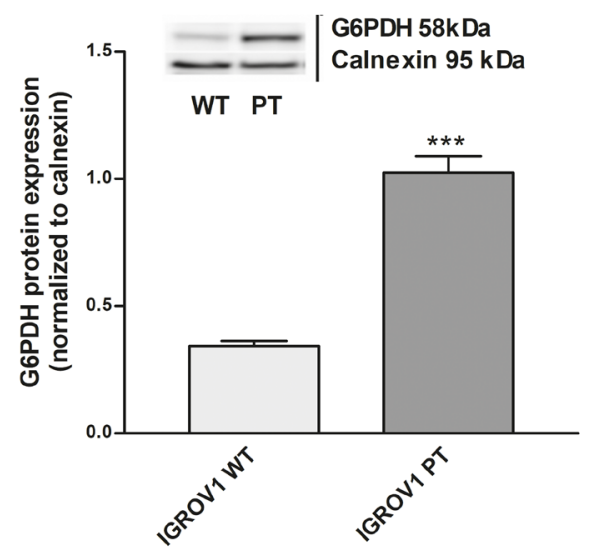

D

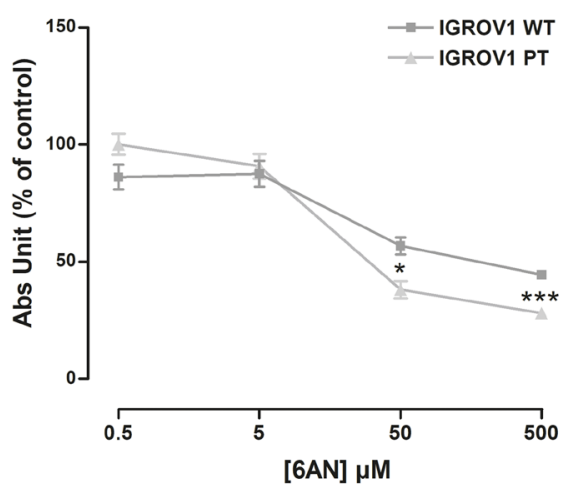

$\mathbf{F}$

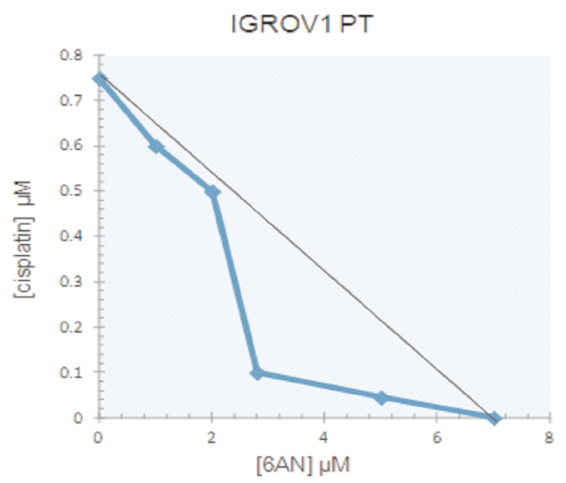

Figure 3: Inhibition of G6PDH, rate-limiting step of PPP, mainly affect cisplatin-resistant cells. (A-C) G6PDH mRNA levels (A), protein expression (B) and enzymatic activity (C) were quantified respectively by qRT-PCR, western blotting and the enzymatic assay kit of Cayman Chemical Company. (D) Effect of 6AN (0.5-500 $\mu \mathrm{M})$ on IGROV1 cell viability after $24+48 \mathrm{~h}$ of treatment. (E-F) Isobologram of cisplatin-sensitive (E) and cisplatin-resistant (F) cells showing the effect of 6-AN in association with cisplatin treatment. Data are expressed as a percentage of control. The graph was obtained using iso-effective drug concentrations causing $25 \%$ of the cytotoxic effect. Data are the mean \pm SEM of at least 3-5 independent cultures. ${ }^{* * *} p<0.001,{ }^{* *} p<0.01,{ }^{*} p<0.05$; IGROV1 PT vs IGROV1 WT. $+++p<0.001$; treatment $v s$ control. 
was more effective with respect to free cisplatin. These data demonstrated that the combination of cisplatin/ $\mathrm{SSL}_{4}$ with inhibition of the PPP enzyme G6PDH can remarkably increase the cytotoxic activity of cisplatin and can overcome cisplatin cancer resistance. In Table 4 the combination index values calculated by the Chou \& Talalay [23] are reported. The same combination was also tested in 2008 and C13 ovarian cancer cell lines confirming the efficacy of the treatment as reported in Supplementary Figure 5.

\section{DISCUSSION}

Chemotherapy remains the principal therapeutic approach in cancer treatment. Despite recent successes, resistance and relapse are still major obstacles [7]. Hence, novel pharmacological strategies addressing such issues are urgently needed.

Nanosized carriers have the potential to improve biopharmaceutical features, pharmacokinetic properties and the therapeutic effectiveness of anticancer drugs [24].
A

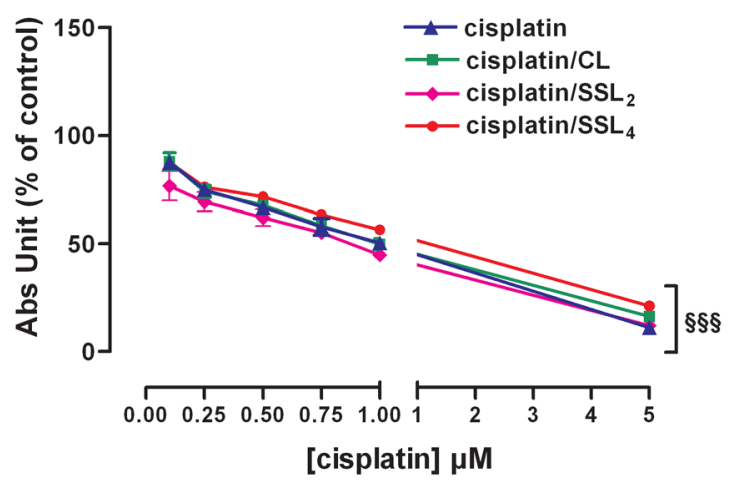

B IGROV1 PT

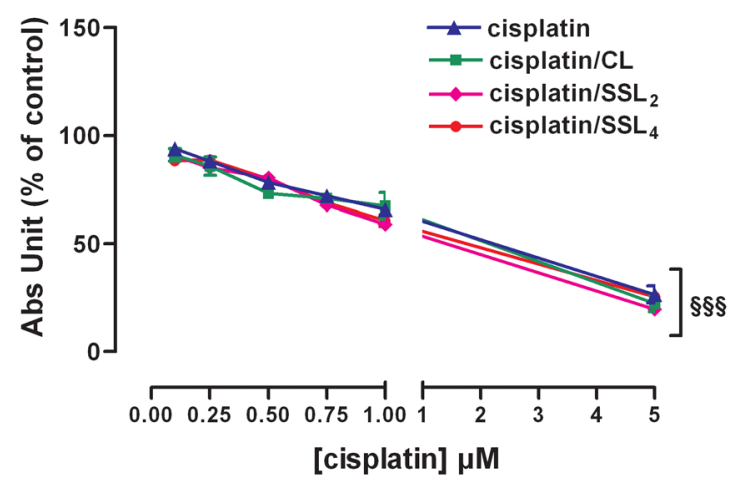

Figure 4: Cisplatin/liposomes delivery does not change cisplatin effectiveness in both IGROV1 cell lines. (A-B) Effect of cisplatin alone or delivered by 3 different liposomal formulations (lyophilized with trehalose) in cisplatin-sensitive (A) and cisplatinresistant (B) cells. The effect was measured after $24+48 \mathrm{~h}$ of treatments by SRB test. Data are the mean \pm SEM of at least 3-4 independent cultures. $\S \S \S \mathrm{p}<0.001$; treatment $v s$ control. Data are expressed as a percentage of control.

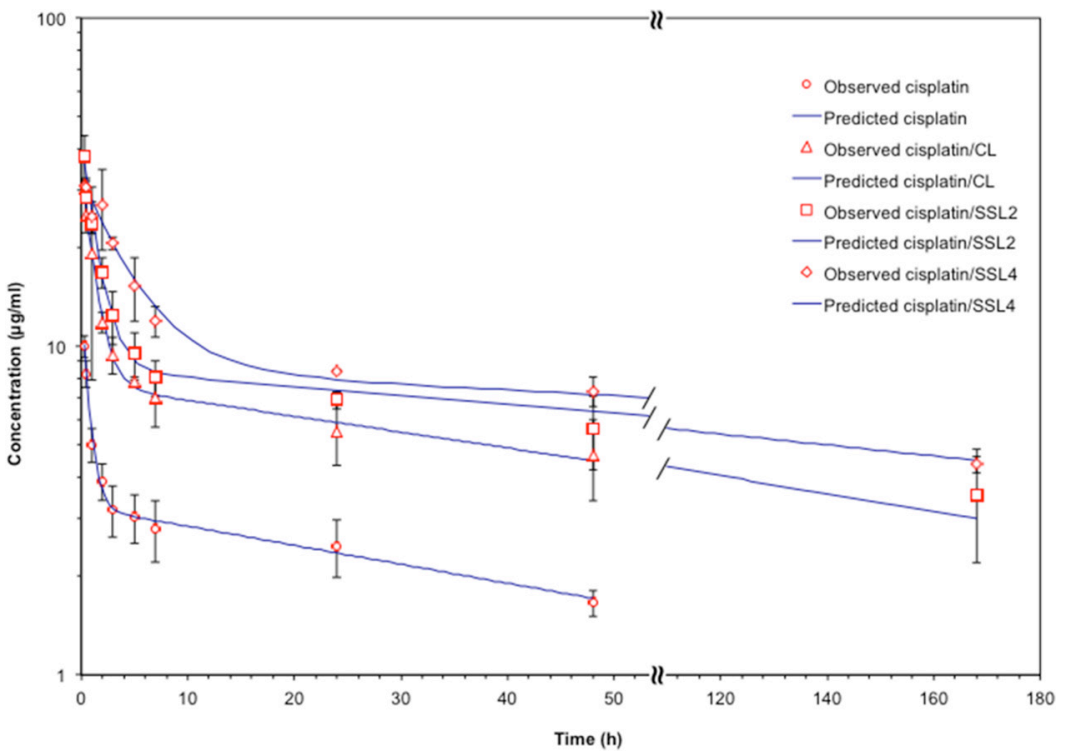

Figure 5: Liposomal formulations of cisplatin showed prolonged pharmacokinetic profiles. Pharmacokinetic profiles of free cisplatin and cisplatin -loaded liposomes $\left(\mathrm{CLs}, \mathrm{SSL}_{2} \mathrm{~s}\right.$. and $\left.\mathrm{SSL}_{4} \mathrm{~s}\right)$ in female Lewis rats ( $\mathrm{n}=3$ per group) after i.v. injection via tail vein of $3 \mathrm{mg} / \mathrm{kg}$ cisplatin equiv. Data are the mean $\pm \mathrm{SEM}$. 
Table 3: Elimination half-life ( $\left.T^{1} / 2 \beta\right)$ and area under the curve (AUC) of free cisplatin and liposomal formulations of cisplatin in Lewis rats $(\mathrm{n}=3)$ after the i.v. injection of $3 \mathrm{mg} / \mathrm{kg}$ of cisplatin equiv

\begin{tabular}{lcc}
\hline Formulation & $\mathbf{T} 1 / 2 \boldsymbol{\beta}(\mathbf{h})$ & $\mathbf{A U C}(\boldsymbol{\mu g} / \mathbf{m l} \cdot \mathbf{h})$ \\
\hline cisplatin & 52.14 & 250.19 \\
cisplatin $/ \mathrm{CL}$ & 62.26 & 719.36 \\
cisplatin $/ \mathrm{SSL}_{2}$ & 110.72 & 1411.57 \\
cisplatin $/ \mathrm{SSL}_{4}$ & 179.81 & 2334.64 \\
\hline
\end{tabular}

In the light of this view, we here report that a cisplatin liposomal formulation, obtained by a new approach of PEGylation, in combination with the PPP inhibitor 6-AN might represent a new therapy approach against cisplatinresistant cancers.

Cisplatin is one of the most used chemotherapy drugs for the treatment of OC, but unfortunately, drug resistance is readily seen in patients during the therapeutic treatment [25]. Furthermore, the clinical use of cisplatin is limited by its severe side effects, including nephrotoxicity and ototoxicity. Dose-related and cumulative renal failure is the major dose-limiting toxicity of cisplatin. A single dose of $50 \mathrm{mg} / \mathrm{m}^{2}$ induced renal toxicity in $28 \%$ to $36 \%$ and ototoxicity in up to $31 \%$ of patients treated. The toxicity, also associated with drug resistance, created the limits in clinical management. Strategies for modifying cisplatin uptake into cancer cells and the pharmacokinetic profile may be useful for reducing toxicity and resistance while increasing therapeutic efficacy [25].

Liposomes are well-known drug delivery systems, already clinically approved, exploited for improving pharmacokinetics, anticancer efficacy, and reducing systemic toxicity of many anticancer drugs. The PEGylated form of liposomes, called stealth liposomes (SLs), represents a smart approach to escape macrophage uptake and gain a prolonged circulation time in blood. Recently, we proposed a new type of PEGylated liposomes in which the hydrophobic anchor, which keeps the polymer attached to the liposome surface, was greatly increased by linking up to four phospholipid moieties to a single PEG chain instead of a single phospholipid (PEGDSPE) as is commonly used in SLs [22]. These new PEG derivatives, namely PEG-DSPE 2 and PEG-DSPE offered an increased stability of the PEG layer around the liposomes, termed SSLs. In the development of new liposomal formulation, it is of fundamental relevance the physicochemical properties of the lipid bilayer that influence the processes of drug encapsulation and release. In particular for cisplatin, phospholipids with a higher temperature of transitions $\left(T_{\mathrm{m}}\right)$, such as HSPC, showed a better retention of the entrapped drug [26]. Taking in mind that our scope was to develop a cisplatin delivery system for the treatment of OC through intraperitoneal injections, we focused on SSLs that can release the entrapped drug within 2-3 days. The preliminary investigation based on liposomes constituted of the unsaturated S75 phospholipid and cholesterol was unsatisfactory because cisplatin was released completely within $24 \mathrm{~h}$. The unsaturated S75 phospholipid increased the fluidity and permeability of the liposome bilayer with respect to saturated lipids. To balance the increased fluidity and improve the stability of the vesicles, one-third of the S75 amount was substituted with the saturated HSPC phospholipid achieving the desired release profile. Nevertheless, such cisplatin release required the development of a lyophilized liposome formulation to avoid drug leakage during storage, which would have hampered the cytotoxicity testing and the potential future exploitation. Trehalose and sucrose were investigated as a cryoprotectant to preserve liposome size and drug encapsulation. Although both agents worked well in the preservation of vesicles morphology, sucrose had the disadvantage to reduce cisplatin activity, especially in the resistant cell line (Supplementary Figure 1), thus further confirming a role of the metabolic pathway in cisplatin resistance. Differently, the cells could not metabolize trehalose; therefore, it was selected as the cryoprotectant for all the tested liposomal formulations. The stabilization offered by the PEG layer on the liposome surface was investigated by a pharmacokinetic study in rats. The profile of cisplatin concentration in plasma for SSLs, and in particular for $\mathrm{SSL}_{4}$, surpasses that of conventional liposomes by showing a clear half-life prolongation and an increase in the AUC values (Table 3).

The second goal of this work was to target specific pathways correlated to cisplatin resistance in order to increase drug efficacy. Cisplatin resistance is generally considered a multi-factorial phenomenon causing, among others, changes in drug transport and accumulation, increases of DNA repair and detoxification systems as well evasion from apoptotic cell death [27]. These alterations might also play a role in the observed different internalization of the cisplatin/ $\mathrm{SSL}_{4} \mathrm{~s}$ between wildtype and resistant cell lines (Figure 6). In the last years, emerging evidence supported the involvement of cell metabolism reprogramming in resistance to cisplatin [28].

G6PDH is the first and rate-limited enzyme of the PPP, which is expressed in almost all cells. Recent studies demonstrated that G6PDH was involved in cell growth 
modulation and carcinogenesis. In previous studies we demonstrated that the overexpression and increased enzymatic activity of G6PDH were correlated to ovarian cisplatin-resistant phenotype cells [10], suggesting that up-regulation of G6PDH activity could be a target to counteract cisplatin resistance. In fact, the combined treatment with the G6PDH inhibitors (6-AN or DHEA)

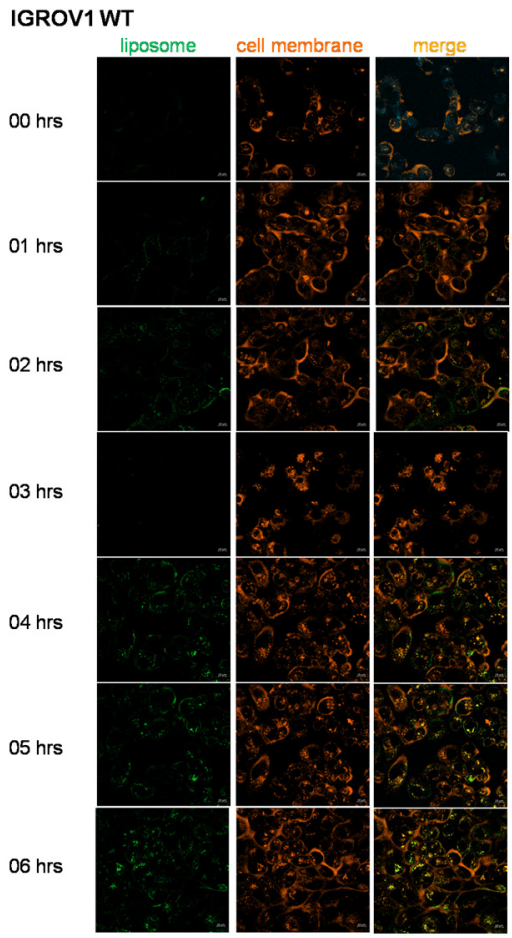

and cisplatin, exhibited a selective additive effect on cisplatin-resistant cells [10].

Present data support that SSLs of cisplatin can become a strategy to counteract cisplatin resistance especially in combination with 6-AN. A combination of cisplatin/ $\mathrm{SSL}_{4}$ with the targeted metabolic inhibition of PPP showed a better efficacy than the cisplatin alone

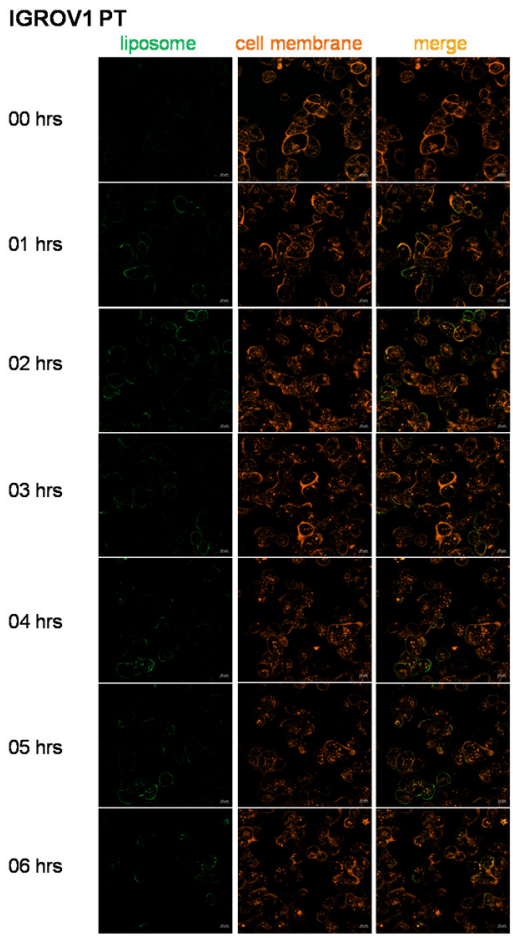

Figura 6: Time-lapse/live confocal laser scanning microscope images of IGROV1 WT and IGROV1 PT incubated with cisplatin $/ \mathbf{S S L}_{4}$. Cells were incubated with fluorescein-labeled cisplatin/ $\mathrm{SSL}_{4} \mathrm{~s} 0.5 \mu \mathrm{M}$ for $6 \mathrm{~h}$. To stain plasma membrane in live cells CellMask ${ }^{\mathrm{TM}}$ Orange Plasma membrane stain was used. Green: liposome, red: cell membrane. Scale bar is $10 \mu \mathrm{m}$.

A

IGROV1 WT

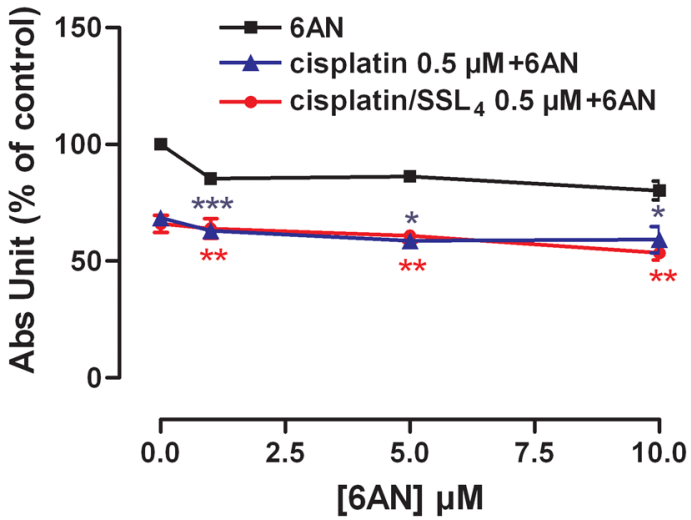

$\begin{array}{ll}\text { B } & \text { IGROV1 PT }\end{array}$

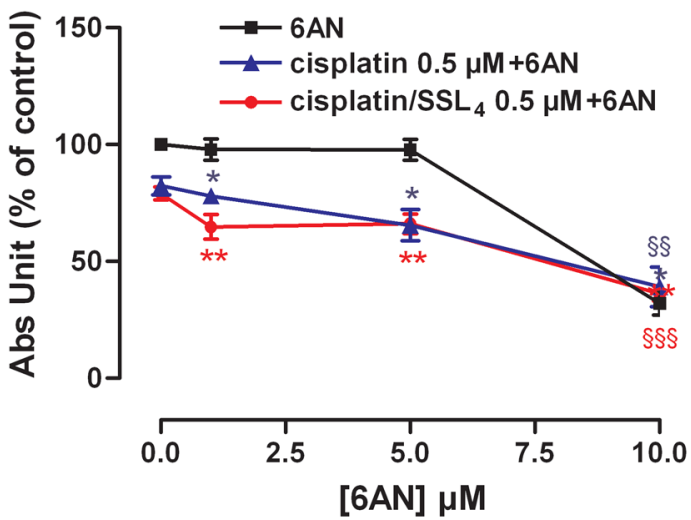

Figure 7: Co-treatment of 6AN and cisplatin/SSL4 increases drug activity in IGROV1 PT cells. (A-B) Effect of 6AN and cisplatin/ $\mathrm{SSL}_{4}$ association in cisplatin-sensitive (A) and cisplatin-resistant (B) cells. The effect was measured after $24+48 \mathrm{~h}$ of treatments by SRB test. Data are the mean \pm SEM of at least $3-4$ independent cultures. ${ }^{* * *} p<0.001,{ }^{* *} p<0.01,{ }^{*} p<0.05$; association $v s 6 \mathrm{AN}$. $\S \S p<0.001$, $\S \S p<0.01$; association $v s$ cisplatin. Data are expressed as a percentage of control. 
Table 4: Combination index of cisplatin/ $\mathrm{SSL}_{4}$ and 6- $\mathrm{AN}$ in wild-type and resistant cell lines

\begin{tabular}{|c|c|c|c|c|c|}
\hline \multirow{2}{*}{ Conc. cisplatin $/ \mathrm{SSL}_{4}(\mu \mathrm{M})$} & \multirow{2}{*}{ Conc. 6AN $(\mu \mathrm{M})$} & \multicolumn{2}{|c|}{ IGROV1 WT } & \multicolumn{2}{|c|}{ IGROV1 PT } \\
\hline & & Effect & CI & Effect & CI \\
\hline 0.1 & 1 & 0.8845 & 7.371 & 0.873 & 0.956 \\
\hline 0.1 & 5 & 0.7382 & 0.316 & 0.811 & 1.176 \\
\hline 0.1 & 10 & 0.676 & 0.211 & 0.327 & 0.552 \\
\hline 0.5 & 1 & 0.6397 & 0.852 & 0,647 & 0.661 \\
\hline 0.5 & 5 & 0.608 & 0.717 & 0.661 & 1.147 \\
\hline 0.5 & 10 & 0.535 & 0.487 & 0.362 & 0.681 \\
\hline
\end{tabular}

(Figure 7). The fact that the cisplatin/ $\mathrm{SSL}_{4}$ had a similar or better cytotoxic effect than cisplatin when both were used in combination with 6-AN, is a promising result in view of the prolonged effect that can be achieved with a liposomal formulation of cisplatin in vivo and the concomitant reduced toxic effect of the drug.

\section{MATERIALS AND METHODS}

\section{Materials}

Non-hydrogenated soy phosphatidylcholine (S75) was a kind gift of Lipoid (Ludwigshafen, DE, Germany); hydrogenated soy phosphatidylcholine (HSPC) and 1,2-distearoyl-sn-glycero-3-phosphoethanolamine (DSPE) were purchased from NOF Corporation (Tokyo, JP). Cisplatin, 6-aminonicotinamide (6-AN), triton $\mathrm{X}-100$, trehalose, sucrose, $o$-phenylenediamine (OPDA), cholesterol (Chol), trypan blue, Sulforhodamine B and all solvents and reagents were obtained from Sigma-Aldrich Co. (Milan, IT). N-(Fluorescein-5-thiocarbamoyl)-1,2dihexadecanoyl-sn-glycero-3-phosphoethanolamine triethylammonium salt (fluorescein-DHPE) was purchased by Invitrogen (USA). PEG5k- $\beta$ Glu-(DSPE) $(\text { PEG-(DSPE) })_{2}$ ) and PEG5k- $\beta$ Glu( $(\beta \text { Glu })_{2}-(\text { DSPE) })_{4}($ PEG$\left.(\mathrm{DSPE})_{4}\right)$ were prepared as described previously [22].

\section{Cell lines}

\section{Human ovarian carcinoma cells}

IGROV1 wild-type and the cisplatin-resistant subclone (kind gift of Dr. Giuseppe Toffoli, CRO Aviano National Cancer Institute, Italy) were grown in a cisplatinfree in Roswell Park Memorial Institute medium (RPMI 1640) supplemented with $10 \%$ fetal bovine serum (FBS), $4 \mathrm{mM}$ glutamine, $100 \mathrm{U} / \mathrm{ml}$ penicillin and $100 \mu \mathrm{g} / \mathrm{ml}$ streptomycin, in humidified condition at $5 \% \mathrm{CO}_{2}$ and $37^{\circ} \mathrm{C}$. Cisplatin-resistant subclones (respectively IGROV1 PT; Supplementary Figure 3) were generated in Toffoli's lab according to previously standardized protocols.
All reagents for cell culture were from Cambrex-Lonza (Basel, Switzerland) and FBS from Gibco, Invitrogen (Carlsbad, CA, USA). The growth kinetics are shown in Supplementary Figure 4.

\section{Preparation of liposomes}

All liposomes were prepared by the thin layer evaporation method. Classic liposomes (CLs) were prepared with S75, HSPC, and cholesterol in a molar ratio of $63: 25: 12$. The molar ratio composition of super stealth liposomes, $\mathrm{SSL}_{2} \mathrm{~s}$ and $\mathrm{SSL}_{4} \mathrm{~s}$, were 60:24:12:4 of S75:HSPC:Chol:PEG-DSPE ${ }_{2}$ or PEG-DSPE ${ }_{4}$, respectively. When required, fluorescent-labeled liposomes were prepared by co-dissolving fluoresceinDHPE $(0.6 \%$ molar with respect to S75) with the lipids. The lipid mixture, composed of about $24.5 \mathrm{mg}$ of phospholipids equiv. divided between the different species according to the ratios above reported, and 2.16 $\mathrm{mg}$ of Chol were dissolved in $0.2 \mathrm{ml}$ of chloroform. A thin lipid film was obtained by evaporation of the organic solvent under a stream of nitrogen $\left(\mathrm{N}_{2}\right)$ and further vacuum-dried for $24 \mathrm{~h}$ to remove any residual organic solvent. The film was hydrated with $1 \mathrm{ml}$ of cisplatin solution at $1 \mathrm{mg} / \mathrm{ml}$ in PBS and the resultant liposomal suspension was incubated at $70^{\circ} \mathrm{C}$ for $1 \mathrm{~h}$ with gentle mixing. Small unilamellar vesicles (SUV) were obtained by serial extrusion cycles through polycarbonate filters with a pore size ranging from 400 to $100 \mathrm{~nm}$ at $70^{\circ} \mathrm{C}$ using a syringe extruder Liposofast (Avestin Inc., CA). The separation of the no-encapsulated drug from the liposomes was achieved by ultrafiltration with an Amicon Ultra centrifugal tube cut-off $10 \mathrm{kDa}$ (Millipore). When needed trehalose as cryoprotectant was added to the hydration solution at different concentrations (cryoprotectant: phospholipid 2:1, 5:1 or 10:1 mass ratio) and to the purification solution (cryoprotectant: phospholipid 6:1, mass ratio). Then the liposomal formulations were frozen at $-80^{\circ} \mathrm{C}$ for $24 \mathrm{~h}$ and, finally, lyophilized. The liposomes were reconstituted to the initial volume by the addition of milliQ water. 


\section{Characterization of cisplatin-loaded liposomes}

\section{Size characterization}

The average particle size and the polydispersity index (PDI) of CLs, $\mathrm{SSL}_{2} \mathrm{~s}$, and $\mathrm{SSL}_{4} \mathrm{~s}$ were measured on a dynamic light scattering (DLS) instrument Zetasizer Nano ZS (Malvern, UK). Phospholipid concentrations in liposome solutions were measured by Stewart assay, based on a colorimetric determination of inorganic phosphate.

\section{Drug loading}

Cisplatin concentration was determined with a spectrometric method developed by Basotra et al [29]. From a solution of liposomal cisplatin aliquots of 20 $\mu \mathrm{L}$ were withdrawn and placed in $1 \mathrm{~mL}$ glass test tubes. Then $100 \mu \mathrm{L}$ of OPDA solution at $1.4 \mathrm{mg} / \mathrm{mL}$ and 200 $\mu \mathrm{L}$ of phosphate buffer $5 \mathrm{mM}$ pH 6.8 were added to each solution and heated at $100^{\circ} \mathrm{C}$ for $10 \mathrm{~min}$ in order to get the formation of a light green color. The solutions were cooled to room temperature, and brought to $1 \mathrm{~mL}$ with DMF. The UV absorption at $706 \mathrm{~nm}$ was measured by a UV-Vis spectrophotometer.

A solution of cisplatin in $5 \mathrm{mM}$ phosphate buffer $\mathrm{pH}$ 6.8 at a concentration of $10 \mu \mathrm{g} / \mathrm{mL}$ was used to prepare a calibration curve.

\section{Serum stability}

An aliquot of about $20 \mathrm{mg}$ in phospholipid equiv. of each cisplatin-loaded liposomes was resuspended in $2 \mathrm{ml}$ of FBS/PBS (50/50) mixture and independently incubated for 24 hours at $37^{\circ} \mathrm{C}$. Samples were analyzed by DLS for $24 \mathrm{~h}$.

\section{Drug release}

$1 \mathrm{~mL}$ of a liposome suspension was loaded into a dialysis tubes (Float-A-Lyzer G2, 100,000 MWCO) and placed in a becker filled with $500 \mathrm{~mL}$ of PBS and kept under stirring. The system was thermostated at $37^{\circ} \mathrm{C}$. Aliquots $(20 \mu \mathrm{L})$ were withdrawn from the dialysis tube at different time points to measure the content of cisplatin as above reported.

\section{Cell viability assays}

\section{Trypan blue exclusion assay}

$1 \times 10^{5}$ cells were plated on 12 -well plates and, following overnight incubation, were exposed to a glucose-free medium added with $1 \mathrm{mM}$ 2-deoxyglucose (2-DG) for 24 hours. After treatment, cells were washed, detached with $0.25 \%$ trypsin- $0.2 \%$ EDTA and suspended in trypan blue at 1:1 ratio in medium solution [30]. Cells were counted using a chamber Burker hemocytometer.

\section{Sulforhodamine B (SRB) test}

$4 \times 10^{3}$ cells were plated on 96-well plates and, following overnight incubation, were exposed to different treatments according to experimental protocols. After treatments cells were fixed with trichloroacetic acid and stained with SRB as previously described [10]. The bound SRB was therefore dissolved by adding $10 \mathrm{mM}$ TRIS and the absorbance was measured at $570 \mathrm{~nm}$ using a Victor3X multilabel plate counter (Wallac Instruments, Turku, Finland).

\section{Immunoblot assay}

$1.5 \times 10^{6}$ cells (IGROV1) were plated in $100 \mathrm{~mm}$ cell culture dish and allowed to attach overnight. After 48 hours, cells were washed and lysed with ice-cold lysis buffer (TRIS $25 \mathrm{mM} \mathrm{pH} \mathrm{7,4;} \mathrm{NaCl} 150 \mathrm{mM}$; IGEPAL $1 \%$; sodium deoxycholate $1 \%$; SDS $0,1 \%$; EDTA $1 \mathrm{mM}$ ) supplemented with the protease inhibitor cocktails (Roche Molecular Biochemicals, Mannheim, Germany). Cell lysates were then centrifuged at $14000 \mathrm{rpm}$ for 15 minutes at $4{ }^{\circ} \mathrm{C}$ and the supernatant protein content was determined by Lowry procedure (Bio-rad DC Protein Assay, MA, USA). Equal amounts of protein $(40 \mu \mathrm{g})$ were loaded on a $10 \%$ polyacrylamide gel and electrophoretically separated in running buffer. After electrophoresis, the proteins were blotted onto a Hybond-P PVDF membrane (Amersham Biosciences, Buckinghamshire, UK) and non-specific binding sites were blocked with a $10 \%$ skim milk solution. The membrane was therefore exposed to the elected primary antibody: anti-GLUT1 (1:2000; AbCam, Cambridge, UK) or anti-G6PDH (1:500; Santa Cruz Biotechnology, Inc., Europe) and, following overnight incubation, was washed and exposed to the HRP-conjugated anti-rabbit secondary antibody (1:3500; PerkinElmer, MA, USA). The signal was visualized with an enhanced chemoluminescent kit (Amersham Biosciences) according to the manufacturer's instructions and analyzed by Molecular Imager VersaDoc MP 4000 (Bio-Rad, Hercules, CA, USA). GLUT1 and G6PDH were normalized to calnexin (1:2000; Rabbit, Santa Cruz Biotechnology). The integrated intensities of GLUT1 and G6PDH were normalized to calnexin.

\section{Quantitative real-time PCR}

Total mRNA was extracted as per manufacturer's instructions using a Direct-zol ${ }^{\mathrm{TM}}$ RNA MiniPrep kit (Zymo Research, Irvine, CA, USA) and measured with a NanoDrop 2000 (Thermo Fischer Scientific Inc., Waltham, MA, USA). The relative expression of each gene was determined by quantitative real-time PCR (Eco ${ }^{\mathrm{TM}}$ Illumina, Real-Time PCR system, San Diego, CA, USA) using One Step SYBR PrimeScript RT-PCR Kit (Takara Bio, Inc., Otsu, Shiga, Japan) and the primers designed as follow: G6PDH: F aagaacgtgaagctccetga $\mathrm{R}$ aatataggggatgggcttgg; GLUT1: F atgggcttctcgaaactggg R ccgcagtacacaccgatgat; PFKM: F gccatcagcctttgacaga R ctccaaaagtcgcatcactg; PGK1: F cagctgctgggtctgtcat, 
R gctggctcggctttaacc; LDHA: F tggcagccttttccttagaa R cgcttccaataacacggttt. Melt-curve analysis was used to confirm the specificity of amplification and absence of primer dimers. All genes were normalized to calnexin designed as follow: $F$ : gaagggaagtggttgctgtg $\mathrm{R}$ : gatgaaggaggagcagtggt. Expression levels of the indicated genes were calculated with the $\Delta \Delta \mathrm{Cq}$ method [31] using the dedicated Eco ${ }^{\mathrm{TM}}$ Software v4.0.7.0. Wild-type cells were used as reference sample. Briefly, this method normalizes the expression of the target genes relative to a single reference gene; thereafter the obtained relative expressions are normalized to a reference sample. The exact calculations are adapted from Livak, et al. as follow: $\Delta \mathrm{Cq}=\mathrm{Cq}_{\text {(Target Assay) }}-\mathrm{Cq}_{\text {(Reference Assay) }} ; \Delta \Delta \mathrm{Cq}=\Delta \mathrm{Cq}_{\text {(Test Sample) }}$ $-\Delta \mathrm{Cq}_{(\text {Reference Sample })} ; \mathrm{RQ}=2^{-\Delta \Delta \mathrm{Cq}}$.

\section{Glucose uptake}

IGROV1 glucose uptake was measured as previously described [10]. Briefly, $5 \times 10^{3}$ cells (IGROV1) were plated in 96-well plate and allowed to attach overnight. After 24 hours, cells were stained for 5 minutes with the glucose analog 6-NBDG (Invitrogen, Paisley, UK) and their fluorescence $\left(\lambda_{\mathrm{ex}}: 465 \mathrm{~nm}, \lambda_{\mathrm{em}}: 540 \mathrm{~nm}\right)$ was measured by Victor3X multilabel plate counter (Wallac Instruments, Turku, Finland).

\section{G6PDH activity}

$1.5 \times 10^{6}$ cells (IGROV1) were plated in $100 \mathrm{~mm}$ cell culture dish and allowed to attach overnight. After 48 hours, cell samples were prepared as previously described [10]. The G6PDH activity was assayed on cell supernatant as per manufacturer's instructions using the Glucose-6Phosphate Dehydrogenase Activity Assay Kit (Cayman Chemical Company, MI, USA). The fluorescence intensity $(\lambda \mathrm{ex} / \mathrm{em}=540 / 585)$ was measured using a Victor3X multilabel plate counter (Wallac Instruments, Turku, Finland). The G6PDH activity (nmol/min/ml) was calculated as per manufacturer's instructions.

\section{Live-cells confocal microscopy}

$25 \times 10^{4}$ cells (IGROV1) were grown in 4-wells glass-bottom culture chambers (Sarstedt AG \& Co, Nümbrecht, Germany) and, after 24 hours, were labeled with LysoTracker ${ }^{\circledR}$ Deep Red (Molecular Probes, Invitrogen) or CellMask ${ }^{\mathrm{TM}}$ Orange Plasma membrane Stains (Molecular Probes, Invitrogen) as per manufacturer's instructions. After staining, cells were washed, loaded with the fluorescent cisplatin/ $\mathrm{SSL}_{4} 0.5 \mu \mathrm{M}$ and the images were periodically acquired for 24 hours using a time-lapse confocal microscope (Zeiss LSM 800, 40X magnification). A volumetric reconstruction was then obtained using the software ZEN 2.1 (blue edition).

\section{Statistical analyses}

All data were analyzed with GraphPad software and are expressed as mean \pm SEM. Standard ANOVA procedures were performed for all the cell viability assays except for the SRB tests after cisplatin and 6-AN treatments that were analyzed with unpaired Student's $t$-tests. One sample $t$-tests were used to analyze results expressed as a ratio of control (qRT-PCR and glucose uptake), while unpaired Student's $t$-tests were performed for all the other results. Significance was considered at $p<0.05$.

\section{Isobolographic analysis}

The isobolographic analysis was used to determine the effect of cisplatin and 6-AN co-treatment. Isoboles are defined as iso-effect curves. that show drug concentrations resulting in equal effect $[32,33]$. From iso-effective curves it is possible to verify the presence of simple additivity, supra-additivity (synergism) or infra-additivity (antagonism).

\section{Ethical statement}

The study protocol was approved by the Ethics Committee of the University of Padova and the Italian Ministry of Health (938/2016-PR), and animals were handled in compliance with national (Italian) Legislative Decree 116/92 guidelines and with the "Guide for the Care and Use of Laboratory Animals" by the National Research Council of the National Academies.

\section{Pharmacokinetic study}

FemaleLewis rats (weight 210-250 g) were purchased from Charles River Labs and housed in a temperature and humidity controlled room under a constant 12-hour light/dark cycle. Animals had free access to water and food ad libitum. Animals were randomly divided into four groups of three units each. Free and liposomal cisplatin, in $\mathrm{CL}, \mathrm{SSL}_{2}$, and $\mathrm{SSL}_{4}$, were injected as a single bolus via tail vein at the concentration of 3 $\mathrm{mg} / \mathrm{kg}$ cisplatin equiv. Blood samples $(100-150 \mu \mathrm{L})$ were withdrawn by the tail-tip cut method at predetermined time-points and placed into heparinized Eppendorf test tubes. Plasma samples were centrifuged at $1000 \mathrm{~g} \times 15$, to eliminate the red blood cells. The supernatant plasma $(50 \mu \mathrm{L})$ were stored at $-80^{\circ} \mathrm{C}$ until the determination of cisplatin by atomic absorption spectroscopy (AAS) on a Varian AA240Z, equipped with a sample dispenser and a graphite tube atomizer, GTA120. Cisplatin concentration in serum samples was measured against a standard curve obtained with a cisplatin standard solution. Each sample was mineralized using a solution of concentrated nitric acid and hydrogen peroxide (34.5-36.5\%) in 1:4 (v:v). The mineralization process comprised four stages: a drying 
stage consisting of 3 steps at temperature of 85,95 and $120^{\circ} \mathrm{C}$ respectively, an ashing stage at $1000^{\circ} \mathrm{C}$ in 3 steps of 5.0, 1.0 and $2.0 \mathrm{~s}$, respectively, an atomization stage at $2700^{\circ} \mathrm{C}$ in 3 steps of $0.9,2.0$ and $2.0 \mathrm{~s}$ and a stage of burning-clean with cooling down at $50^{\circ} \mathrm{C}$.

The instrument was operated at a wavelength of $265.9 \mathrm{~nm}$ with a slit band of $0.2 \mathrm{~nm}$. Each sample was analyzed in duplicate and the absorbance values were averaged.

The pharmacokinetic data elaboration was performed by PkSolver software by applying a bicompartmental model [34].

\section{Author contributions}

DC, SN and VC carried out the experimental work.

MS offered technical contribution to the animal experiment.

AP offered technical contribution to the confocal experiment.

ER performed statistical analysis

MM and GP designed and supervised the study and write the paper.

\section{ACKNOWLEDGMENTS}

The work was supported by the Italian Association for Cancer Research (AIRC; MFAG \#15458) and by the Italian Ministry of Health (Ricerca Finalizzata GR-201102351128). DC was supported by a fellowship from "Fondazione Umberto Veronesi".

\section{CONFLICTS OF INTEREST}

The authors declare no conflicts of interest.

\section{FUNDING}

The work was supported by the Italian Association for Cancer Research (AIRC; MFAG \#15458) and by the Italian Ministry of Health (Ricerca Finalizzata GR-201102351128). DC was supported by a fellowship from "Fondazione Umberto Veronesi".

\section{REFERENCES}

1. Ferlay J, Soerjomataram I, Dikshit R, Eser S, Mathers C, Rebelo M, Parkin DM, Forman D, Bray F. Cancer incidence and mortality worldwide: sources, methods and major patterns in GLOBOCAN 2012. Int J Cancer. 2015; 136:E359-E386.

2. Fagotti A, Fanfani F, Vizzielli G, Gallotta V, Ercoli A, Paglia A, Costantini B, Vigliotta M, Scambia G, Ferrandina G. Should laparoscopy be included in the work-up of advanced ovarian cancer patients attempting interval debulking surgery? Gynecol Oncol. 2010; 116:72-77.

3. Bristow RE. Advanced cytoreductive surgery in gynecologic oncology. Gynecol Oncol. 2009; 114:S1-2.

4. Ozols RF. Challenges for chemotherapy in ovarian cancer. Ann Oncol. 2006; 17:181-187.

5. Joerger M, Huitema AD, Richel DJ, Dittrich C, Pavlidis N, Briasoulis E, Vermorken JB, Strocchi E, Martoni A, Sorio R, Sleeboom HP, Izquierdo MA, Jodrell DI, et al. Population pharmacokinetics and pharmacodynamics of paclitaxel and carboplatin in ovarian cancer patients: a study by the European organization for research and treatment of cancer-pharmacology and molecular mechanisms group and new drug development group. Clin Cancer Res. 2007; 13:6410-6418.

6. Vella N, Aiello M, Russo AE, Scalisi A, Spandidos DA, Toffoli G, Sorio R, Libra M, Stivala F. 'Genetic profiling' and ovarian cancer therapy. Mol Med Rep. 2011; 4:771-777.

7. Cannistra SA. Cancer of the ovary. N Engl J Med. 2004; 351:2519-2529.

8. Markman M. Chemotherapy-induced peripheral neuropathy: underreported and underappreciated. Curr Pain Headache Rep. 2006; 10:275-78.

9. Montopoli M, Bellanda M, Lonardoni F, Ragazzi E, Dorigo P, Froldi G, Mammi S, Caparrotta L. "Metabolic reprogramming" in ovarian cancer cells resistant to cisplatin. Curr Cancer Drug Targets. 2011; 11:226-35.

10. Catanzaro D, Gaude E, Orso G, Giordano C, Guzzo G, Rasola A, Ragazzi E, Caparrotta L, Frezza C, Montopoli M. Inhibition of Glucose-6-phosphate dehydrogenase sensitizes cisplatin resistant cells to death. Oncotarget. 2015; 6: 30102-14. https://doi.org/10.18632/oncotarget.4945.

11. Stölting DP, Koch M, Wiese M, Royer HD, Bendas G. Liposomal cisplatin can overcome chemotherapy resistance of A2780 ovarian cancer cells by inducing the extrinsic apoptotic pathway. Int J Clin Pharmacol Ther. 2014; 52:78-81.

12. Casagrande N, Celegato $M$, Borghese C, Mongiat M, Colombatti A, Aldinucci D. Preclinical activity of the liposomal cisplatin lipoplatin in ovarian cancer. Clin Cancer Res. 2014; 20:5496-506.

13. Fantini M, Gianni L, Santelmo C, Drudi F, Castellani C, Affatato A, Nicolini M, Ravaioli A. Lipoplatin treatment in lung and breast cancer. Chemother Res Pract. 2011; 2011:125192.

14. Stathopoulos GP, Boulikas T. Lipoplatin formulation review article. J Drug Deliv. 2012; 2012:581363.

15. Stathopoulos GP, Boulikas T, Kourvetaris A, Stathopoulos J. Liposomal oxaliplatin in the treatment of advanced cancer: a phase I study. Anticancer Res. 2006; 26:1489-1493.

16. Kieler-Ferguson HM, Chan D, Sockolosky J, Finney L, Maxey E, Vogt S, Szoka FC Jr. Encapsulation, controlled release, and antitumor efficacy of cisplatin delivered in liposomes composed of sterol-modified phospholipids. Eur J Pharm Sci. 2017; 103:85-93. 
17. Ringhieri P, Pannunzio A, Boccarelli A, Morelli G, Coluccia M, Tesauro D. Effect of cisplatin containing liposomes formulated by unsaturated chain-containing lipids on gynecological tumor cells. J Liposome Res. 2016; 26:307-312.

18. Allen TM, Hansen C, Martin F, Redemann C, Yau-Young A. Liposomes containing synthetic lipid derivatives of poly(ethylene glycol) show prolonged circulation half-lives in vivo. Biochim Biophys Acta. 1991; 1066:29-36.

19. Gabizon A, Catane R, Uziely B, Kaufman B, Safra T, Cohen R, Martin F, Huang A, Barenholz Y. Prolonged circulation time and enhanced accumulation in malignant exudates of doxorubicin encapsulated in polyethyleneglycol coated liposomes. Cancer Res. 1994; 54:987-992.

20. Parr MJ, Ansell SM, Choi LS, Cullis PR. Factors influencing the retention and chemical stability of poly(ethylene glycol)-lipid conjugates incorporated into large unilamellar vesicles. Biochim Biophys Acta. 1994; 1195:21-30.

21. Crielaard BJ, Yousefi A, Schillemans JP, Vermehren C, Buyens K, Braeckmans K, Lammers T, Storm G. An in vitro assay based on surface plasmon resonance to predict the in vivo circulation kinetics of liposomes. J Control Release. 2011; 156:307-314.

22. Pasut G, Paolino D, Celia C, Mero A, Joseph AS, Wolfram J, Cosco D, Schiavon O, Shen H, Fresta M. Polyethylene glycol (PEG)-dendron phospholipids as innovative constructs for the preparation of super stealth liposomes for anticancer therapy. J Control Release. 2015; 199:106-113.

23. Chou TC, Talalay P. Quantitative analysis of dose-effect relationships: the combined effects of multiple drugs or enzyme inhibitors. Adv Enzyme Regul. 1984; 22:27-55.

24. Hu Q, Sun W, Wang C, Gu Z. Recent advances of cocktail chemotherapy by combination drug delivery systems. Adv Drug Deliv Rev. 2016; 98:19-34.

25. Peng H, Jin H, Zhuo H, Huang H. Enhanced antitumor efficacy of cisplatin for treating ovarian cancer in vitro and in vivo via transferrin binding. Oncotarget. 2017; 8:4559745611. https://doi.org/10.18632/oncotarget.17316.

26. Alavizadeh SH, Badiee A, Golmohammadzadeh S, Jaafari MR. The influence of phospholipid on the physicochemical properties and anti-tumor efficacy of liposomes encapsulating cisplatin in mice bearing C26 colon carcinoma. Int J Pharm. 2014; 473:326-333.

27. Galluzzi L, Senovilla L, Vitale I, Michels J, Martins I, Kepp O, Castedo M, Kroemer G. Molecular mechanisms of cisplatin resistance. Oncogene. 2012; 31:1869-1883.

28. Liu H, Liu Y, Zhang JT. A new mechanism of drug resistance in breast cancer cells: fatty acid synthase overexpression-mediated palmitate overproduction. Mol Cancer Ther. 2008; 7:263-270.

29. Basotra M, Singh SK, Gulati M. Development and Validation of a Simple and Sensitive Spectrometric Method for Estimation of Cisplatin Hydrochloride in Tablet Dosage Forms: Application to Dissolution Studies. ISRN Analytical Chemistry. 2013; 2013:1-8, Article ID 936254.

30. Strober W. Trypan blue exclusion test of cell viability. Curr Protoc Immunol. 2001; 3:3B.

31. Livak KJ, Schmittgen TD. Analysis of relative gene expression data using real-time quantitative PCR and the 2(-Delta Delta C(T)) Method. Methods. 2001; 25:402-8.

32. Loewe $\mathrm{S}$. The problem of synergism and antagonism of combined drugs. Arzneimittelforschung. 1953; 3:285-90.

33. Tallarida RJ. An overview of drug combination analysis with isobolograms. J Pharmacol Exp Ther. 2006; 319:1-7.

34. Zhang Y, Huo M, Zhou J, Xie S. PKSolver: An add-in program for pharmacokinetic and pharmacodynamic data analysis in Microsoft Excel. Comput Methods Programs Biomed. 2010; 99:306-14. 